\title{
Effects of Different Amino Acids on Biofilm Growth, Swimming Motility and Twitching Motility in Escherichia Coli BL21
}

\author{
Seh Nee Goh \\ Department of Biological Science, Faculty of Science, Universiti Tunku Abdul Rahman \\ Jalan Universiti, Bandar Barat, 31900 Kampar, Perak, Malaysia \\ E-mail: nicolegoh91@1utar.my
}

Amie Fernandez

Department of Biological Science, Faculty of Science, Universiti Tunku Abdul Rahman Jalan Universiti, Bandar Barat, 31900 Kampar, Perak, Malaysia

E-mail: amieferz@1utar.my

See Zou Ang

Department of Bioscience, Faculty of Science, Universiti Tunku Abdul Rahman

Jalan Universiti, Bandar Barat, 31900 Kampar, Perak, Malaysia

E-mail: angseezou@1utar.my

Wai Yip Lau

Department of Biological Science, Faculty of Science, Universiti Tunku Abdul Rahman Jalan Universiti, Bandar Barat, 31900 Kampar, Perak, Malaysia E-mail: 1004923@1utar.my

\section{Di Lin Ng}

Department of Biological Science, Faculty of Science, Universiti Tunku Abdul Rahman Jalan Universiti, Bandar Barat, 31900 Kampar, Perak, Malaysia 
E-mail: ngdilin@hotmail.com

Eddy Seong Guan Cheah

Department of Biological Science, Faculty of Science, Universiti Tunku Abdul Rahman

Jalan Universiti, Bandar Barat, 31900 Kampar, Perak, Malaysia

E-mail: cheahsg@utar.edu.my

Received: February 2, 2013 Accepted: February 19, 2013

doi:10.5296/jbls.v4i2.3195 URL: http://dx.doi.org/10.5296/jbls.v4i2.3195

\begin{abstract}
Biofilms are surface-attached, matrix-enclosed microbial communities that can cause various diseases like formation of dental plague, urinary tract infection and cystic fibrosis. The purpose of this study was to examine the effects of amino acids (arginine, valine, leucine, glycine, lysine, phenylalanine, threonine and proline) on biofilm formation swimming motility and twitching motility in Escherichia coli BL21. M63 minimal salt media (supplemented with different types and concentrations of amino acids) were used for induction of biofilm formation and the resulting biofilm growth was quantified spectrophotometrically at optical density of $550 \mathrm{~nm}$ after 24 hours of inoculation. For swimming and twitching motility assays, amino acid-supplemented tryptone and Luria-Bertani agar plates were used and the diameter of halo formed in the agar was measured after the same duration. The eight amino acids tested showed varied effects on biofilm formation, swimming motility and twitching motility in E. coli BL21. Leucine, glycine, threonine and proline promoted both twitching and swimming motility up to about $100 \%$. Arginine and valine increased swimming motility up to $50 \%$ but had no effect on twitching motility. Lysine and phenylalanine completely inhibited both swimming and twitching motility in the bacteria. With regard to biofilm formation, both leucine and valine promoted it up to a maximum of $25 \%$. However, glycine, lysine, phenylalanine, and threonine inhibited biofilm formation; proline and arginine showed inhibitory effects only at higher concentrations $(0.4 \%)$. These results suggest that amino acids may play a role in inhibiting or promoting biofilm formation. The potential use of amino acid-based dietary supplements to control biofilm formation and ultimately to treat its associated diseases warrants further investigation.
\end{abstract}

Keywords: Amino Acids, Biofilm Formation, Swimming Motility, Twitching Motility

\title{
1. Introduction
}

Bacteria are predominantly not free floating but grow as multi-species communities attached to submerged surfaces known as biofilms (O'Toole \& Kolter, 1998; Stoodley et al., 2002). 


\section{Macrothink}

Biofilms are highly organized and functionally heterogeneous bacterial communities that are frequently formed on biotic and abiotic surfaces. They protect bacteria from the harsh external environment via self-produced matrices of extracellular polymeric substances (Kolari, 2003). Furthermore, they are also more resistant to antimicrobial agents, compared to the same bacteria growing in a free-swimming (planktonic) state (Costerton et al., 1999; Donlan \& Costerton, 2002; Dunne, 2002).

Escherichia coli is a rod-shaped, Gram-negative bacterium commonly found in the lower intestine of warm-blooded animals. It was used as a model in this study for biofilm formation. Biofilms can be beneficial as filters in wastewater treatment plants, whereby waste organic matters will be taken up by the bacterial cells in them as source of nutrients (Cunningham et al., 2008). On the other hand, biofilms can cause serious economic and health problems due to their enhanced resistance to antibiotics and biofouling potential (Costerton et al., 1999). Furthermore, they are also responsible for huge losses in industrial productivity (Imran \& Smith, 2005).

In this study, we investigated the effects of amino acids on biofilm formation, swimming motility and twitching motility in E. coli BL21. Different amino acids in various concentrations were tested with the aim of identifying the amino acid(s) that would exert effects, both positive and negative, on these physiological processes. According to Hewitt (2010), twitching motility is a prerequisite for biofilm formation. . Twitching is a surface-associated motility that involves the extension, tethering and retraction of the polar type IV pili (Alarcon et al., 2009). According to Barrionuevo and Vullo (2012), the presence of flagella allows bacterial cells to propagate through liquid or medium of very low viscosity. The formation of complex bacterial communities known as biofilms begins with the interaction of planktonic cells with a surface in response to appropriate environmental signals (O’Toole \& Kolter, 1998). Kraigsley et al. (2001) has shown that non-swimming or non-twitching bacteria have reduced ability of biofilm formation.

To observe the effects of different amino acids on biofilm formation as well as twitching and swimming motility, we therefore supplemented the growth media of $E$. coli BL21 with different concentrations of arginine, valine, proline, phenylalanine, leucine, glycine, lysine and threonine for the assays performed.

\section{Materials and Methods}

\subsection{Bacterial Strains and Medium Preparation}

The bacterial strain used in this study was E. coli BL21, which was obtained from the American Type Culture Collection (ATCC BAA-1025). E. coli BL21 was maintained on Luria-Bertani (LB) agar plates ( $1 \% \mathrm{w} / \mathrm{v}$ tryptone, $0.5 \% \mathrm{w} / \mathrm{v}$ yeast extract, $0.5 \% \mathrm{w} / \mathrm{v} \mathrm{NaCl}$ and $1.5 \% \mathrm{w} / \mathrm{v}$ agar). The amino acid stock solutions were prepared by dissolving amino acids in distilled water, followed by sterilization via autoclaving. These were added to molten LB agar to achieve different concentrations of amino acids $(0 \%, 0.05 \%, 0.1 \%, 0.2 \%$ and $0.4 \% \mathrm{v} / \mathrm{v})$, respectively, in the final plates. 


\subsection{Biofilm Formation Assays}

Biofilm formation assays were performed using 96-well microtiter plates, based on the protocol by Merritt (2011) with minor modifications. Briefly, E. coli was cultured in LB broth overnight and the resulting culture was diluted to approximately $\mathrm{OD}_{600 \mathrm{~nm}}$ of 0.6 with filter-sterilized M63 minimal salt medium (13.6 g/L KH $\mathrm{KH}_{4}, 2 \mathrm{~g} / \mathrm{L}\left(\mathrm{NH}_{4}\right)_{2} \mathrm{SO}_{4}, 0.5 \mathrm{mg} / \mathrm{L}$ $\mathrm{FeSO}_{4} .7 \mathrm{H}_{2} \mathrm{O} 1 \mathrm{mM} \mathrm{MgSO}_{4}$ and $0.2 \% \mathrm{w} / \mathrm{v}$ glucose). Each well of a microtitre plate was loaded with $100 \mu 1$ of M63 minimal salt medium and different concentrations of each amino acid $(0.05 \%, 0.1 \%, 0.2 \%$ and $0.4 \% \mathrm{v} / \mathrm{v})$, as well as a control well without any amino acid. Each concentration for every amino acid tested was assayed in triplicate. The plate was then sealed and incubated at $37^{\circ} \mathrm{C}$ for 24 hours.

Planktonic bacteria were removed by shaking the dish over a waste tray. The plate was then washed by submerging it in a tray filled with sterile distilled water. Subsequently, $0.1 \% \mathrm{w} / \mathrm{v}$ crystal violet solution was added to each well and the plate was left to stain for 10 minutes at room temperature. Next, the crystal violet solution was removed by submerging the plate in a water tray. The plate was then inverted and tapped on paper towels to remove excess liquid and left to air dry. The stained wells were then treated with $30 \% \mathrm{v} / \mathrm{v}$ acetic acid for 15 minutes at room temperature to solubilize the dye. The bacterial suspension in each well was mixed well by pipetting and its optical density was measured in a microplate reader (Tecan, Austria) at 550 nm.

\subsection{Swimming Motility Assays}

Swimming motility assays were performed on tryptone agar plates ( $1 \% \mathrm{w} / \mathrm{v}$ tryptone, $0.5 \% \mathrm{w} / \mathrm{v}$ $\mathrm{NaCl}$ and $0.3 \%$ w/v agar) supplemented with different concentrations of amino acids (as above). The inocula were diluted overnight culture of $E$. coli in tryptone broth (approximately $\mathrm{OD}_{600}$ of 0.6). Following spot inoculation, the plates were incubated at $37^{\circ} \mathrm{C}$ for 24 hours. The diameter of the halo formed in the agar was then measured using the ImageJ software (downloaded from http://rsbweb.nih.gov/ij/).

\subsection{Twitching Motility Assays}

Twitching motility assays were performed on LB agar plates ( $1 \% \mathrm{w} / \mathrm{v}$ tryptone, $0.5 \% \mathrm{w} / \mathrm{v}$ yeast extract, $0.5 \% \mathrm{w} / \mathrm{v} \mathrm{NaCl}$ and $1 \% \mathrm{w} / \mathrm{v}$ agar) supplemented with different concentrations of amino acids (as above). The inocula were diluted overnight culture of E. coli in LB broth (approximately $\mathrm{OD}_{600}$ of 0.6). Following spot inoculation, the plates were incubated at $37^{\circ} \mathrm{C}$ for 24 hours. The diameter of the halo formed in the agar was then measured using the ImageJ software.

\subsection{Statistical Analysis}

One-way analysis of variance (ANOVA) was performed using SPSS to determine the statistical significance of all experimental data at $\mathrm{p}<0.05$. 


\section{MInstitute Macrothink $^{\text {Int }}$}

\section{Results}

3.1 Effects of Different Types and Concentrations of Amino Acids on Biofilm Formation

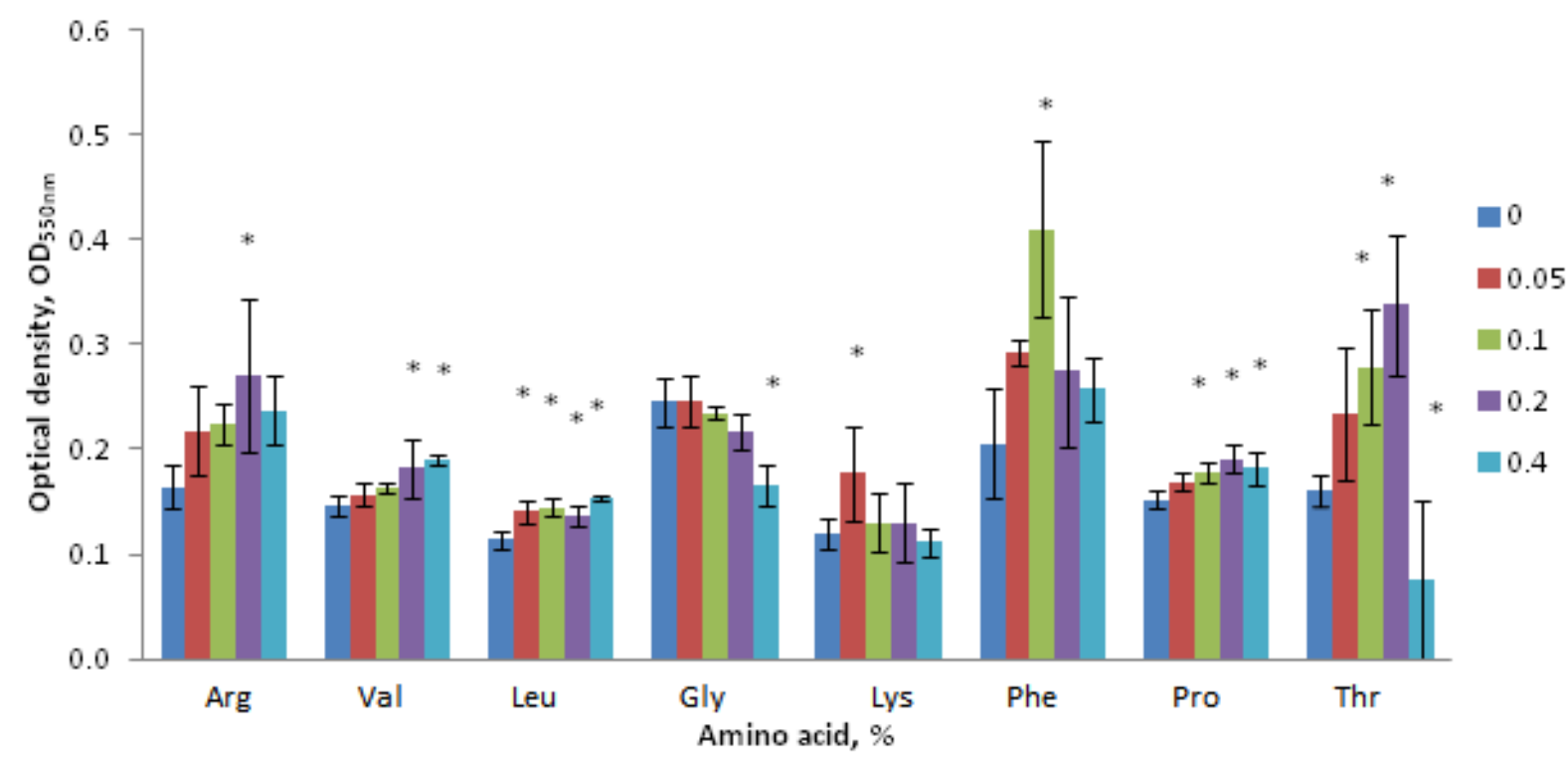

Figure 1. Effects of different types and concentrations of amino acids on biofilm formation in $E$. coli.

Biofilm formation in E. coli BL21 was measured spectrophotometrically following incubation in the presence of different types of amino acids in various concentrations. Asterisk $(*)$ indicates value that is significantly different to that for the M63 medium with no added amino acid by ANOVA at $\mathrm{p}<0.05$.

Biofilm formation assays were performed using different types and concentrations of amino acids (Figure 1). Several amino acids were observed to induce biofilm formation. With increasing concentration of arginine, the OD also increased correspondingly until the concentration of $0.2 \%$; the increment was significant at this concentration. Biofilm formation was significantly increased at $0.2 \%$ concentration from an average of $0.154 \mathrm{~cm}^{2}$ to $0.27 \mathrm{~cm}^{2}$. Increased concentrations of valine also resulted in significant increase in biofilm formation at concentrations of $0.2 \%$ (from an average of $0.146 \mathrm{~cm}^{2}$ to $0.182 \mathrm{~cm}^{2}$ ) and $0.4 \%$ (from an average of $0.146 \mathrm{~cm}^{2}$ to $0.191 \mathrm{~cm}^{2}$ ).

From Figure 1, lysine was observed to induce biofilm growth significantly at the concentration of $0.05 \%$, from an average of $0.120 \mathrm{~cm}^{2}$ to $0.178 \mathrm{~cm}^{2}$. Phenylalanine was observed to increase biofilm growth significantly at $0.1 \%$ concentration, from $0.205 \mathrm{~cm}^{2}$ to $0.4 \mathrm{~cm}^{2}$. As for proline, a significant increase at $0.1 \%$ concentration onwards was observed, from an average of 0.139 $\mathrm{cm}^{2}$ to $0.159 \mathrm{~cm}^{2}$.

Threonine was observed to increase biofilm growth significantly at concentrations of $0.1 \%$, from an average of $0.216 \mathrm{~cm}^{2}$ to $0.312 \mathrm{~cm}^{2}$, and $0.2 \%$, from an average of $0.278 \mathrm{~cm}^{2}$ to 0.409 $\mathrm{cm}^{2}$. The addition of leucine resulted in increased biofilm formation in E. coli BL21 for all concentrations. However, as the amino acid concentration was increased, the biofilm formation 


\section{Macrothink}

did not increase significantly.

On the other hand, glycine showed an inhibitory effect on biofilm formation and the extent of inhibition was concentration-dependent. With regard to this, a significant decrease in biofilm growth was observed at $0.4 \%$ concentration, from an average of $0.246 \mathrm{~cm}^{2}$ to $0.165 \mathrm{~cm}^{2}$. Similarly, threonine at $0.4 \%$ concentration significantly inhibited biofilm formation in E. coli, from an average of $0.244 \mathrm{~cm}^{2}$ to $0.351 \mathrm{~cm}^{2}$.

\subsection{Effects of Different Types and Concentrations of Amino Acids On Swimming Motility}

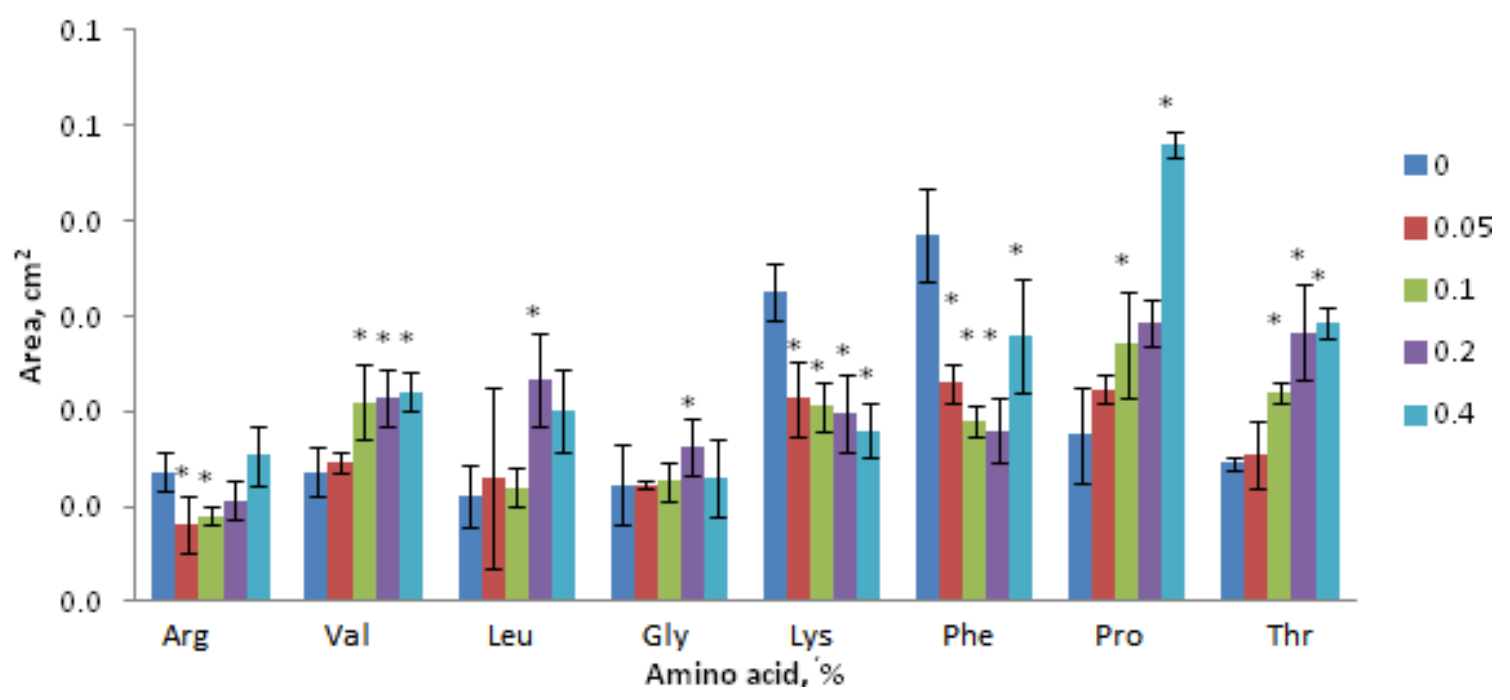

Figure 2. Effects of different types and concentrations of amino acids on swimming motility in E. coli.

Swimming motility in E. coli BL21 was measured following incubation in the presence of different types of amino acids in various concentrations. Asterisk (*) indicates value that is significantly different to that for the tryptone agar plate with no added amino acid by ANOVA at $\mathrm{p}<0.05$.

Swimming motility assays were performed using different types and concentrations of amino acids (Figure 2). A few amino acids were shown to induce biofilm formation. For valine, a significant increase in the size of the halo formed, from $0.014 \mathrm{~cm}^{2}$ to $0.022 \mathrm{~cm}^{2}$, was observed from the concentration of $0.1 \%$ onwards.

According to Figure 2, leucine promoted swimming motility in E. coli BL21 significantly at $0.2 \%$ concentration, from $0.011 \mathrm{~cm}^{2}$ to $0.023 \mathrm{~cm}^{2}$. As for glycine, there was a significant increase in its swimming motility at the same concentration, from $0.012 \mathrm{~cm}^{2}$ to $0.016 \mathrm{~cm}^{2}$. Proline significantly enhanced swimming motility in E. coli at concentrations of $0.1 \%$ and $0.4 \%$, where the diameter of the halo formed increased from $0.021 \mathrm{~cm}^{2}$ to $0.024 \mathrm{~cm}^{2}$ and from $0.047 \mathrm{~cm}^{2}$ to $0.049 \mathrm{~cm}^{2}$, respectively. As for threonine, it also significantly promoted its swimming motility from $0.1 \%$ concentration onwards, from $0.0145 \mathrm{~cm}^{2}$ to $0.0293 \mathrm{~cm}^{2}$.

On the other hand, some amino acids were inhibitory to swimming motility in E. coli BL21. Based on Figure 2, concentrations of $0.05 \%$ and $0.1 \%$ arginine were shown to suppress 


\section{Macrothink}

swimming motility significantly, from $0.014 \mathrm{~cm}^{2}$ to $0.008 \mathrm{~cm}^{2}$ and from $0.014 \mathrm{~cm}^{2}$ to $0.009 \mathrm{~cm}^{2}$, respectively. Both lysine and phenylalanine significantly suppressed the swimming motility of the cells from $0.05 \%$ concentration onwards (from $0.033 \mathrm{~cm}^{2}$ to $0.018 \mathrm{~cm}^{2}$ and from $0.039 \mathrm{~cm}^{2}$ to $0.028 \mathrm{~cm}^{2}$, respectively).

\subsection{Effects of Different Types and Concentrations of Amino Acids on Twitching Motility}

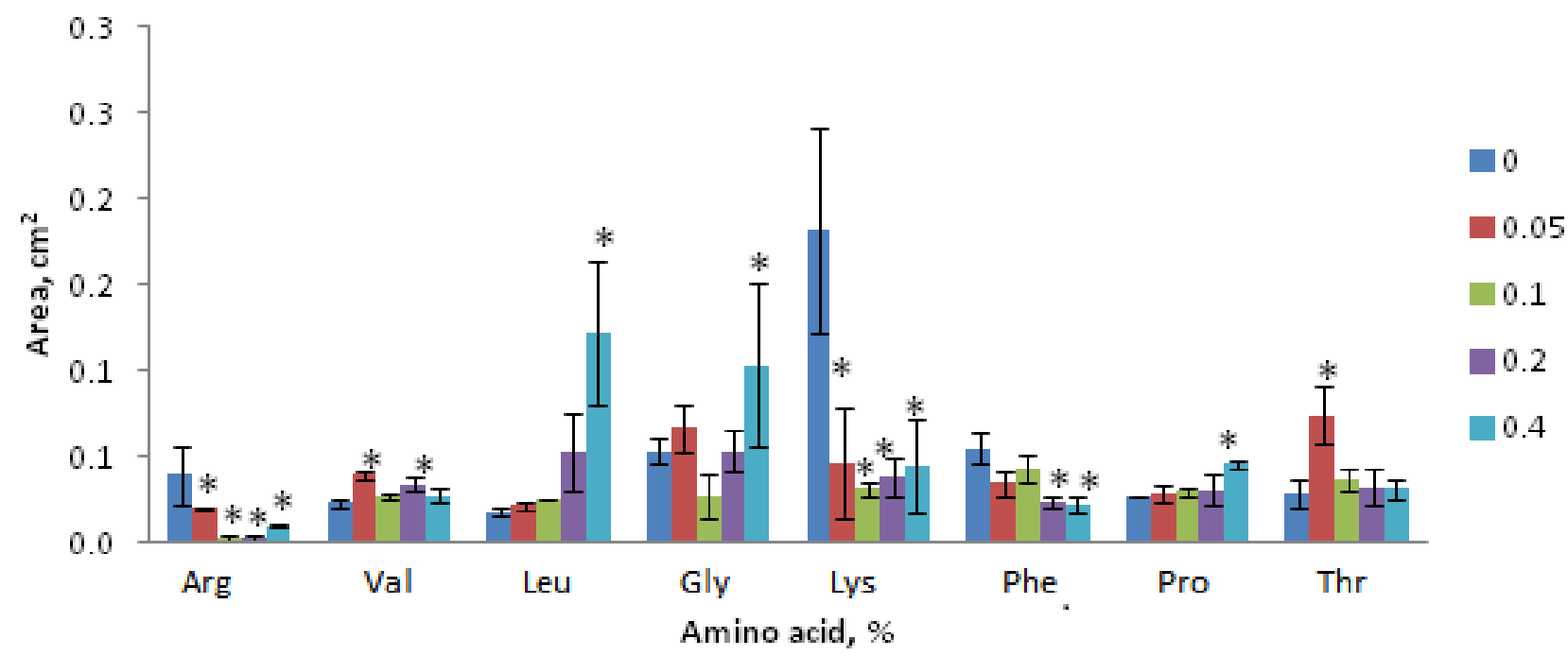

Figure 3. Effects of different types and concentrations of amino acids in various concentrations on twitching motility in E. coli.

Twitching motility in E. coli BL21 was measured following incubation in the presence of different types of amino acids in various concentrations. Asterisk (*) indicates value that is significantly different to that for the LB agar plate with no added amino acid by ANOVA at $\mathrm{p}<$ 0.05 .

For bacterial cells to induce biofilm formation, they require the ability to twitch (Hewitt, 2010). According to Figure 3, several amino acids increased twitching motility in E. coli BL21. Leucine and glycine significantly increased the diameter of the halo formed at $0.4 \%$ concentration, from $0.0178 \mathrm{~cm}^{2}$ to $0.121 \mathrm{~cm}^{2}$, and from $0.053 \mathrm{~cm}^{2}$ to $0.1 \mathrm{~cm}^{2}$, respectively. Similarly, valine significantly increased twitching motility in E. coli BL21 at concentrations of $0.05 \%$ and $0.2 \%$, from $0.023 \mathrm{~cm}^{2}$ to $0.039 \mathrm{~cm}^{2}$ and from $0.023 \mathrm{~cm}^{2}$ to $0.033 \mathrm{~cm}^{2}$, respectively. For proline, only the $0.4 \%$ concentration significantly increased twitching motility, from $0.0265 \mathrm{~cm}^{2}$ to $0.0303 \mathrm{~cm}^{2}$. For threonine, only the $0.05 \%$ concentration significantly induced twitching motility, from $0.028 \mathrm{~cm}^{2}$ to $0.074 \mathrm{~cm}^{2}$.

However, arginine significantly inhibited the twitching ability of E. coli BL21 for all concentrations, from $0.039 \mathrm{~cm}^{2}$ to $0.009 \mathrm{~cm}^{2}$. Lysine significantly suppressed twitching from $0.05 \%$ concentration onwards, from $0.181 \mathrm{~cm}^{2}$ to $0.044 \mathrm{~cm}^{2}$. Phenylalanine also significantly reduced twitching at concentrations $0.2 \%$ and $0.4 \%$, from $0.054 \mathrm{~cm}^{2}$ to $0.023 \mathrm{~cm}^{2}$, and from $0.054 \mathrm{~cm}^{2}$ to $0.021 \mathrm{~cm}^{2}$, respectively. 


\section{Discussion}

Based on the results obtained (Figure 1), arginine was shown to promote biofilm formation at $0.2 \%$ concentration. An evidence of arginine promoting biofilm formation can be observed in the study by Yen et al. (2002), whereby arginine favorably promoted biofilm formation in Desulfovibrio vulgaris Hildenborough of wild type, mega-plasmid deletion strain and a fur deletion mutant. Weiss et al. (2007) has also shown that arginine was necessary for biofilm maturation. Furthermore, the capability of arginine to promote biofilm formation in Pseudomonas aeruginosa was demonstrated by Bernier et al. (2011), whereby the use of arginine as the sole carbon source actually promoted biofilm formation by almost three-fold.

However, arginine was shown to inhibit swimming motility in E. coli BL21 significantly at concentrations of $0.05 \%$ and $0.1 \%$. This is consistent with the study by Atsumi et al. (2006), in which they reported that arginine can inhibit the $\mathrm{Na}^{+}$-driven flagellar motors of alkaliphilic Bacillus spp. by competing with the $\mathrm{Na}^{+}$for the molecular targets.

Similarly, arginine also inhibited twitching motility in E. coli BL21, whereby the gradual increase of arginine concentration from $0 \%$ to $0.4 \%$ resulted in a consistent trend of significant decrease in biofilm formation (Figure 3). This phenomenon of inhibition of twitching motility by arginine has been reported by Cugini et al. (2012), in which they observed that the arginine deiminase secreted by Streptococcus intermedius inhibited biofilm formation in the commensal pathogen Porphyromonas gingivalis. This is achieved via downregulation of genes encoding the major ( $f i m A)$ and minor ( $m f a l$ ) fimbriae, both of which are required for proper biofilm development (Cugini et al., 2012). Arginine deiminase is an enzyme that catalyzes the hydrolysis of L-arginine to L-citrulline and ammonia gas (Gong et al., 2000). This can thus imply that the availability of arginine could result in the inhibition of long fimbriae expression, which is crucial for twitching motility and eventually bacterial adherence to surfaces.

According to Bernier et al. (2011), valine is one of the amino acids that robustly promoted biofilm formation in $P$. aeruginosa. This is because valine is used by $P$. aeruginosa as the carbon and energy source for growth. This is coherent with our results, which showed that in the twitching motility assay, there was a significant increase in the size of the halo formed at $0.05 \%$ and $0.2 \%$ concentrations of valine (Figure 3); while in the swimming motility assay, there was a significant increase in its size from the concentration of $0.1 \%$ onwards (Figure 2). Overall, at valine concentration of $0.2 \%$, swimming motility, twitching motility and biofilm formation was increased significantly (Figures 1-3). This is contrary to results obtained by Valle et al. (2008), in which they showed that the accumulation of valine in biofilms formed by many Gram-negative bacteria can actually inhibit the growth of several E. coli strains.

Figure 2 and Figure 3 showed that leucine and glycine both promoted swimming and twitching motility in E. coli BL21. However, based on Figure 1, only leucine significantly increased biofilm formation while $0.4 \%$ glycine significantly inhibited biofilm development in $E$. coli BL21. This observation is consistent with those reported by Bernier et al. (2011). Leucine amino peptidase, an enzyme in leucine metabolism, was known to be essential for bacterial survival and biofilm formation (Singh et al., 2012). However, D-leucine inhibited biofilm formation in Staphylococcus aureus. D-amino acids did not prevent the initial surface 
attachment of cells but blocked the subsequent growth of the foci into larger assemblies of cells (Hochbaum et al., 2011). These differences may be due to the different isomers of amino acids and species of bacteria used.

In our study, glycine was observed to inhibit biofilm formation in E. coli BL21 (Figure 1). This observation was also reported by Luengpailin \& Doyle (2000). When glycine was incorporated into the growth medium, Streptococcus sobrinus exhibited diminished ability to aggregate with high molecular-weight $\alpha$-1,6-glucan and lowered lectin activities (Luengpailin \& Doyle, 2000). Since lectin is an important component essential for biofilm formation, it is postulated that the lack of lectin will lead to the inhibition of biofilm formation.

Both lysine and phenylalanine suppressed swimming and twitching motility in E. coli BL21 (Figures 2 and 3). The ability of phenylalanine to induce biofilm formation has been reported in P. aeruginosa (Bernier et al., 2011). Based on Figures 1 3, 0.1\% phenylalanine is the only concentration that significantly induced both biofilm formation and twitching motility in $E$. coli BL21. This might be attributed to the effect of phenylalanine on type IV pili. Phenylalanine acts as the N-terminal for mature pili, cellular appendages that would indirectly increase the ability of cells to adhere to surfaces (Schmidt, 2004).

Pantazaki et al. (2010) reported that lysine can improve biofilm formation. Besides, lysine was assumed to have similar functions to poly-L-lysine, which is the homo-polypeptide for lysine that has the ability to improve adherence to mammalian cells and also to stabilize the attachment of biofilms to surfaces (Cheng et al., 2010). Based on Figure 1, lysine significantly induced biofilm formation at the concentration of $0.05 \%$.

However, higher concentrations of lysine did not significantly increase biofilm formation (Figure 1). Also, lysine significantly inhibited swimming and twitching motility (Figures 2 and 3). This might be due to the presence of lysine decarboxylase in E. coli cells. Lysine decarboxylase is an enzyme that converts lysine into cadaverine, and thus limiting lysine availability for initial growth of biofilms (Lohinai et al., 2010). Higher concentrations of lysine may trigger higher expression of lysine decarboxylase, leading to lesser amount of lysine present in the medium.

According to Figures 2 and 3, threonine has an observable effect on the motility of E. coli BL21; it significantly promoted swimming and twitching motility at concentrations of $0.1 \%$ and $0.05 \%$, respectively. However, as Figure 1 has shown, threonine significantly inhibited biofilm formation at $0.4 \%$ concentration. The expression of type IV pili is believed to increase in the presence of threonine. Furthermore, Berggren et al. (1998) has shown that type IV pili were necessary for biofilm-forming signal transduction in Neisseria spp. Besides, threonine has also been shown to promote swimming motility in bacteria. Morehouse et al. (2005) has shown that threonine is present in the rotor protein FliG, which is important for rotation of flagella in term of directionality. This might explain how threonine enhanced the swimming motility in E. coli BL21 in this study.

As shown in Figure 1, proline significantly increased biofilm formation as well as swimming and twitching motility in E. coli BL21. Blair et al. (1999) has shown that mutation of the 
proline residue in MotA protein will inhibit bacterial swimming motility. MotA is an integral membrane protein that is believed to play a role in proton conduction and stator formation in the flagellar motor in order to obtain energy for the motility. Jain and Pandey (2002) have shown that in order for $E$. coli to carry out chemotaxis, proline is one of the essential compounds that must be present in the surrounding medium.

\section{Conclusion}

Taken together, although it seems that most of the amino acids tested in this study induced biofilm formation in E. coli BL21 (arginine, valine, leucine, lysine, phenylalanine, proline and threonine), they did not necessarily increase swimming and twitching motility as well. Several amino acids inhibited both swimming and twitching motility but induced biofilm formation (arginine, lysine and phenylalanine). Only valine, leucine and proline were observed to induce biofilm formation, swimming motility and twitching motility simultaneously. The findings from this study would contribute to future investigation on the potential use of amino acid-based dietary supplements for the treatment or the control of microbial diseases associated with uncontrolled growth of biofilms. For instance, valine, leucine and proline can be omitted from therapeutic agents to counter biofilm growth.

\section{Acknowledgement}

The authors would like to express their heartfelt gratitude to the Faculty of Science, Universiti Tunku Abdul Rahman for providing the necessary reagents and equipments for this study.

\section{References}

Alarcon, I., Evans, D. J., \& Fleiszig, S. M. J., (2009). The role of twitching motility in Pseudomonas aeruginosa exit from and translocation of corneal epithelial cells. Ophthamol. Vis. Sci., 50, pp. 2237-2244. http://dx.doi.org/10.1167/iovs.08-2785

Atsumi, T., Yoshimura, F., \& Sugiyama, S., (2006). Arginine inhibits Na-driven flagellar motors of alkaliphilic Bacillus. FEMS Microbiol. Lett., 256(2), pp. 224-228. DOI: 10.111/j.1574-6968.2006.00117.x.

Barrionuevo, M. R., \& Vullo, D. L., (2012). Bacterial swimming, swarming and chemotactic response to heavy metal presence: which could be the influence on wastewater biotreatment efficiency. World J. Microbial Biotechnol., 28, 2813-2825, DOI 10.10007/s 11274012-1091-5.

Berggren, P. O., S, I, Mohamed., Josson, A. B., \& Kallstrom, H., (1998). Cell signaling by the type IV pili of pathogenic Neisseria. J. Biol. Chem., 273(34), 21777-21782. http://dx.doi.org/10.1126/science.1065467

Bernier, S. P., Ha, D. G., Khan, W., Merritt, J. H., \& O’Toole, G. A., (2011). Modulation of Pseudomonas aeruginosa surface-associated group behaviors by individual amino acids through c-di-GMP signaling. Res. in Microbiol., 162, 680-688. http://dx.doi.org/10.1016/j.resmic.2011.04.014 
Blair, D. F., Braun, T. F., Empey, J. C., Gully, J. B., Putnam, A., \& Way, S. V., (1999). Function of proline residues of MotA in torque generation by the flagellar motor of Escherichia coli. $J$. Bacteriol., 181(11), 3542-3551.

Cheng, A., Meyer, M., Dykstra, P. \& Ghodssi, R. (2010). Optimizing bacterial adhesion to a microfluidic device for monitoring bacterial biofilm growth. Merit Bien 2010 final report. 1-5.

Costerton, J. W., Stewart, P. S., \& Greenberg, E. P., (1999). Bacterial biofilms: a common cause of persistent infections. Science, 284, 1318-1322. http://dx.doi.org/10.1126/science.284.5418.1318

Cugini, C., Stephens, D. N., Nguyen, D., Kantarci, A., \& Davey, M. E., (2012). Arginine Deiminase Inhibits $P$. gingivalis Surface Attachment. Microbiology, in press.

Cunningham, A. B, Lennox, J. E., \& Ross, R. J., (2008). How do biofilms impact our world? [online] Available at: http://biofilmbook.hypertextbookshop.com/v003/r002/contents/chapters/chapter001/section0 03/blue/page001.html (Accessed: 21 December 2012).

Donlan, R. M., \& Costerton, J. W., (2002). Biofilms: survival mechanisms of clinically relevant microorganisms. Clin. Microbiol Rev., 15, 167-193. DOI: 10,1128/CMR 15.2.167-193.2002.

Dunne, W. M. Jr., (2002). Bacterial adhesion: seen any good biofilms lately? Clin .Microbiol Rev., 15, 155-166. http://dx.doi.org/10.1128/CMR.15.2.155-166.2002

Gong, H., Zolzer, F., Recklinghausen, G. V., Havers, W. \& Schweigerer, L., (2000). Arginine deiminase inhibits proliferation of human leukemia cells more potently than asparaginase by inducing cell cycle arrest and apoptosis. Leukemia, 14(5), 826-829. http://dx.doi.org/10.1038/sj.leu.2401763

Hewitt, J. A., (2010). A comparative study of Pseudomonas aeruginosa strain. Master thesis, University of Notre Dame.

Hochbaum, A. I, Kolodkin-Gal, I., Foulston, L., Kolter, R., Aizenberg, J., \& Losick, R., (2011). Inhibitory effects of d-amino acids on Staphylococcus aureus biofilm development. $J$. Bacteriol. 193(20), 5616-5622. http://dx.doi.org/10.1128/JB.05534-11

Imran, M., \& Smith, H., (2005). Biofilms and the plasmid maintenance question. Math Biosci. 193, 183-204. http://dx.doi.org/10.1016/j.mbs.2004.10.008

Jain, R. K., \& Pandey, G., (2002). Bacterial chemotoxis toward environmental pollutants: role in bioremediation. Appl. Environ. Microbiol., 68(12), 5789-5795. http://dx.doi.org/10.1128/AEM.68.12.5789-5795.2002

Kolari, M., (2003). Attachment mechanisms and properties of bacterial biofilms on non-living surfaces. Masters thesis, University of Helsinki.

Kolodkin, G. I, Romero, D., Cao, S., Clardy, J., Kolter, R., \& Losick, R., (2010). D-amino acids trigger biofilm disassembly. Science, 328, 627-629. http://dx.doi.org/10.1126/science.1188628 
Kolter, R., \& O’Toole, G. A. (1998). Flagellar and twitching motility are necessary for Pseudomonas aeruginosa biofilm development. Mol. Microbiol., 30(2), 295-304. http://dx.doi.org/10.1046/j.1365-2958.1998.01062.x

Kraigsley, A., Ronney, P. D., \& Finkel, S. E., (2002). Hydrodynamic influences on biofilm formation and growth [online]. Available at: http://carambola.usc.edu/research/biophysics/biofilms4web.html [Accessed: 21 December 2012].

Lohinai, Z., Keremi, B., Szoko, E., Tabi, T., Szabo, C., Tullassay, Z., \& Levine, M., (2010). Lysine availability may regulate plaque formation and gingival inflammation. [online]. Available: http://iadr.confex.com/iadr/2010barce/webprogram/Paper133688.html (Accessed: 21 December 2012).

Luengpailin, J., \& Dolye, R. J. (2000). Glycine prevents the phenotypic expression of streptococcal glucan-binding lectin. $B B B A, \quad 1474(2), \quad 212-218$. http://dx.doi.org/10.1016/S0304-4165(00)00010-6

Morehouse, K. A, Goodfellow, I. G., \& Sockett, R. E., (2005). A chimeric N-terminal Escherichia coli-C-terminal Rhodobacter sphaeroiders FliG rotor protein supports bidirectional E. coli flagellar rotation and chemotaxis. J Bacteriol, 187(5), 1695-1701. http://dx.doi.org/10.1128/JB.187.5.1695-1701.2005

O’Toole, G. A., \& Kolter, R., (1998). Flagellar and twitching motility are necessary for Pseudomonas aeruginosa biofilm development. Molecular Microbiology, 30(2), 295-304. http://dx.doi.org/10.1046/j.1365-2958.1998.01062.x

Pantazaki, A. A., \& Kissa, A. (2010). Rhamnolipids are involved in swarming motility and biofilm formation and are induced by amino acids in T. thermophilus. Front. Pharmacol. Conference Abstract: 8th Southeast European Congress on Xenobiotic Metabolism and Toxicity (XEMET 2010).

Schmidt, A., \& Herwals, H., (2004). Contributions to Microbiology, $12^{\text {th }}$ ed., Switzerland, Reinhardt Drunck, Basel, pp.72-73.

Stoodley, P., Sauer, K., Davies, D. G., \& Costerton, J. W., (2002). Biofilms as complex differentiated communities. Annu. Rev. Microbiol., 56, 187-209. http://dx.doi.org/10.1146/annurev.micro.56.012302.160705

Singh, A. K., Singh, R., Tomar, D., Pandya, C. D., \& Singh, R. (2012). The leucine aminopeptidase of Staphylococcus aureus is secreted and contributes to biofilm formation. Int. J. Infectious Diseases. 16(5), 375-381. http://dx.doi.org/10.1016/j.ijid.2012.01.009

Valle, J., Re, S. D., Schmid, S., Skurnik, D., D'Ari, R., \& Ghigo J. M., (2008). The amino acid valine is secreted in continuous-flow bacterial biofilms. J. Bacteriol., 190(1), 264-274. http://dx.doi.org/10.1128/JB.01405-07

Weiss, E. C., Zhu, Y. F., Otto, M., Fey, P. D., Smeltzer, M. S., \& Somerville, G. A., (2007). Staphylococcus aureus biofilm metabolism and the influence of arginine on polysaccharide 


\section{Macrothink}

intercellular adhesin synthesis, biofilm formation, and pathogenesis. Infect. and Immun., 75(9), 4219-4226. http://dx.doi.org/10.1128/IAI.00509-07

Yen, H. C. B., Bender, K., Fields, M. W. \& Wall, J. D., (2002). Desulfovibrio vulgaris Hildenborough biofilm formation by wild type, the mega-plasmid deletion strain, and a fur deletion mutant. [online] Available: http://vimss.lbl.gov/publicfiles/ESPP-Biofilm1_Yen.pdf (Accessed: 15 December 2012).

\section{Copyright Disclaimer}

Copyright reserved by the authors.

This article is an open-access article distributed under the terms and conditions of the Creative Commons Attribution license (http://creativecommons.Org/licenses/by/3.0/) 